\title{
Effect of Bacillus subtilis natto-fermented Radix astragali on collagen production in human skin fibroblasts
}

\author{
Mei-Fang Hsu, Been-Huang Chiang* \\ Institute of Food Science and Technology, National Taiwan University, No. 1, Section 4, Roosevelt Road, Taipei 106, Taiwan, ROC
}

\section{A R T I C L E I N F O}

\section{Article history:}

Received 28 February 2008

Received in revised form 21 June 2008

Accepted 17 September 2008

\section{Keywords:}

Radix astragali

Bacillus subtilis natto

Fermentation

Collagen

Human dermal fibroblasts

\begin{abstract}
A B S T R A C T
Radix astragali was fermented with Bacillus subtilis natto, and the effect of fermented products (HQB) and non-fermented products (HQNB) on collagen production in human dermal fibroblasts (HDF) were investigated. It was found that HQNB significantly improved cell growth and proliferation of HDF cells. However, the enzyme-linked immunosorbent assay and Western blot analysis demonstrated that HQB, but not HQNB, significantly and dose-dependently stimulated the biosynthesis of type I procollagen in both aged ( $81 \mathrm{y}$ ) and young ( $22 \mathrm{y}$ ) HDF cells. Real-time reverse transcription-polymerase chain reaction revealed that expression of type I, type III procollagen and transforming growth factor $\beta 1$ (TGF- $\beta 1$ ) mRNA was significantly stronger in HQB-treated HDF cells than that of HQNB-treated and un-treated HDF cells, suggesting that there was a close correlation between the mRNA expression and protein production in the fibroblasts response to HQB stimulation. The results also suggested that HQB could stimulate the collagen biosynthesis in human dermal fibroblasts, which is, at least in part, associated with the regulation of procollagen biosynthesis resulting from HQB-induced TGF- $\beta 1$ expression and the mitogenic activity in HDF cells, and therefore, is expected to reduce the age-dependent loss of extracellular matrix proteins.
\end{abstract}

(c) 2008 Elsevier Ltd. All rights reserved.

\section{Introduction}

Skin aging is a complicated biological phenomenon. The biochemical changes associated with skin aging include reduced expression of type I collagen messenger ribonucleic acid (mRNA), overexpression of matrix metalloproteinase (MMPs), and decreased synthesis of extracellular matrix (ECM), which results in increased collagen degradation and leads to skin laxity, atrophy, wrinkles, dryness, and other clinical manifestations of skin $[1,2]$. Type I collagen is the main component of the ECM of skin dermis; it provides strength and maintains the structure of the skin dermis. The quantity and quality of collagen are determined by the balance between degradation and synthesis [3]. Collagen degradation is mainly regulated by MMPs, while collagen synthesis is mediated by both transcriptional and post-translational processes. Therefore, it is generally believed that aging process of skin can be improved by promoting collagen synthesis and reducing MMPs activities in the skin.

In recent years, the use of traditional herbal medicines in skin care cosmetics has claimed tremendous attention. Chinese herbs

\footnotetext{
* Corresponding author. Tel.: +886 2 33662415; fax: +886223620849.

E-mail address: bhchiang@ntu.edu.tw (B.-H. Chiang).
}

are of particular interest because they have been applied in skincare products for more than 5000 years. It has been reported that some components in herbal extracts, such as isoflavones, polyphenols, asiaticoside and gallated catechins could enhance collagen production due to their hormone-like or antioxidant effects [4-7]. Radix astragali (root of Astragalus, known as Huangqi in Chinese; family Leguminosae) is one of the most popular Chinese herbs, which is used traditionally to boost energy, strengthen the immune system, and promote skin growth. The components that are most often associated with the healthpromoting activities of $R$. astragali are isoflavonoids, triterpene saponins and polysaccharides $[8,9]$. Recent studies showed that $R$. astragali has significant mitogenic activity and can enhance cellular metabolism and increase the life span of cells [10-13]. Therefore, there is a great deal of interest in studying the role of $R$. astragali preparations in skincare function.

Chinese herbs have long been processed via microbial fermentation. Studies have demonstrated that fermentation not only alters the original bioactivities of Chinese herbs, resulting in new treatment effects, but also enhances the original treatment efficacy [14-16]. It is known that $\beta$-glucosidase from Bacillus subtilis natto can convert isoflavone glucosides to their aglycones [17]. Numerous studies have revealed that the biological effects of isoflavone stem from their aglycones $[18,19]$, and isoflavone aglycones are more 
easily and rapidly absorbed in the intestines [20]. Since $R$. astragali has been traditionally used for skincare, and its active components, such as isoflavones and saponins, are glucosides, it is of great interest to know and compare the effects of non-fermented and fermented preparations of $R$. astragali on collagen production in human skin cells. Therefore, the objectives of this study were to investigate the effect of B. subtilis natto-fermented Radix astragali (HQB) on collagen synthesis in the cultures of human dermal fibroblasts, and their inhibitory effects on the matrix-degrading enzymes (collagenase, elastase, and gelatinase).

\section{Materials and methods}

\subsection{Plant material}

Astragalus membranaceus (Fisch.) Bge. var. mongholicus (Bge.) Hsiao, a commonly used species of Radix astragali supplied by Microbio Co. Ltd. (Taipei, Taiwan) was used in this study, and the authenticity was confirmed by Pharmaconosy Pharmaceutical Technology Division, Biomedical Engineering Research Laboratories, Industrial Technology Research Institute (Hsinchu, Taiwan). The specimens were deposited in the Institute of Food Science and Technology, National Taiwan University, Taipei, Taiwan.

\subsection{Microorganism and culture}

Bacillus subtilis natto (ATCC 7059) was maintained and subcultured in nutrient broth (NB) flasks. A. membranaceus var. mongholicus was milled with a grinder and used as the fermentation medium. Seed culture of $B$. subtilis natto was prepared by transferring $0.1 \mathrm{~mL}$ of bacteria from the NB flask into a 300-mL Erelenmeyer flask containing $100 \mathrm{~mL}$ of NB medium and cultured in shaker at $37^{\circ} \mathrm{C}, 120 \mathrm{rpm}$ for $12 \mathrm{~h}$. The fermentation medium contained $10 \mathrm{~g}$ A. membranaceus var. mongholicus powder and $90 \mathrm{~g}$ water and was inoculated with $0.1 \%$ of the seed culture and then cultivated at $37^{\circ} \mathrm{C}, 120 \mathrm{rpm}$ for $48 \mathrm{~h}$. As the control, the $10 \%$ A. membranaceus var. mongholicus medium was also incubated at the same condition without inoculation. After fermentation or incubation, the broth was centrifuged at $10,000 \mathrm{rpm}$ for $25 \mathrm{~min}$. The supernatant was filtered by Whatman no. 42 paper, freeze-dried, and stored at $-20^{\circ} \mathrm{C}$ for further experiments. All fermentation experiments were performed in triplicate to ensure the reproducibility. Normally, $2.92 \mathrm{~g}$ of dried powder can be obtained from $10 \mathrm{~g}$ of $A$. membranaceus var. mongholicus.

\subsection{Assay for enzyme inhibition activities}

Collagenase, gelatinase, and elastase inhibition activities were measured with EnzChek $^{\mathbb{R}}$ Collagenase/gelatinase and Elastase Assay Kits (Invitrogen Life Technologies Inc., USA) according to the manufacturer's recommendations. In brief, the reaction mixture was prepared by mixing $80 \mu \mathrm{L}$ of the sample or provided inhibitor, $20 \mu \mathrm{L}$ of the substrate solution (collagen or gelatin or elastin), and $100 \mu \mathrm{L}$ of the enzyme. The reaction mixture was incubated at room temperature for an appropriate time and then fluorescence intensity measured by a fluorescence microplate reader (TECAN Spectrofluor Plus, Maennedorf, Switzerland) set for excitation at $485 \mathrm{~nm}$ and emission detection at $535 \mathrm{~nm}$. The inhibition rate was calculated following the formula provided by the manufacturer.

\subsection{Cell culture}

Primary cultures of two normal human dermal fibroblasts (HDF, Cat. C-013-5C, Cascade Biologics, Inc., Portland, OR) derived from adult skin were purchased from Cascade Biologics Company. Both primary fibroblasts were from female donors, $22 \mathrm{y}\left(\mathrm{HDF}_{22 \mathrm{y}}\right)$ and $81 \mathrm{y}\left(\mathrm{HDF}_{81 \mathrm{y}}\right)$, respectively. They were cultured in DMEM medium (Invitrogen Life Technologies Inc., USA) supplemented with 10\% FBS in 95\% air and $5 \% \mathrm{CO}_{2}$ humidified atmosphere at $37^{\circ} \mathrm{C}$.

\subsection{Assay of cell viability}

The MTT colorimetric method [21] was used to determine the cell cytotoxicity and proliferation. Briefly, cells were cultured in 24 -well plates at $1 \times 10^{5}$ cells/well for cytotoxicity determination, and at $4 \times 10^{4}$ cells/well for proliferation study. After the cells were incubated for $24 \mathrm{~h}$, various concentrations of samples were added and incubated for additional time periods. At the end of incubation, tetrazolium dye was added as an indicator in order to convert tetrazolium salts to a colored product, formazan. The formazan concentration was measured by spectrophotometer at $570 \mathrm{~nm}$.

\subsection{Dertermination of type I procollagen synthesis}

To measure type I procollagen biosynthesis specifically, human dermal fibroblasts were plated in 24 -well plates $\left(4 \times 10^{4}\right.$ cells/well). When the cells reached subconfluence in the subculture after $72 \mathrm{~h}$, cells were incubated in the absence or presence of the sample. As positive control, $1 \mathrm{ng} / \mathrm{mL}$ transforming growth factor beta (TGF- $\beta 1$ ) was used. At the end of incubation, cell culture supernatants were collected and analyzed for type I procollagen by enzyme-linked immunosorbent assay (ELISA) according to the manufacturer's protocol (Procollagen Type I C-Peptide EIA kit, TaKaRa Biomedicals Inc., Japan) [7]. Data were normalized to the protein content (Pierce Biotechnology Inc., USA) of the respective cell culture supernatant. Procollagen content of the control group is set to $100 \%$.

Type I procollagen protein levels were assessed by Western blot analysis using the protocol described elsewhere [22] with slight modification. In brief, $25 \mu \mathrm{g}$ of protein was electroblotted onto a nitrocellulose membrane (Amersham Biosciences, UK), following separation using 7.5\% SDS-polyacrylamide gel electrophoresis. The transblotted membranes were blocked with $5 \%$ nonfat milk in Tris-buffer plus $0.1 \%$ Tween-20 for $1 \mathrm{~h}$ at room temperature. The membranes were incubated overnight at $4{ }^{\circ} \mathrm{C}$ with a monoclonal antiprocollagen type I aminoterminal extension peptide (SP1.D8) antibody (Developmental Studies Hybridoma Bank, University of Iowa, Iowa), and then incubated with horseradish peroxidaseconjugated secondary antibody (Cell Signaling Technology Inc., USA) for $1 \mathrm{~h}$ at room temperature. $\beta$-Actin was used as internal control. The immunoreactive bands were detected by an ECL Plus detection kit (Pierce Biotechnology Inc., USA), and visualized and quantified by SYNGENE G:BOX fluorescence and chemiluminescence system (Cambridge, UK).

\subsection{Total RNA isolation and quantitative reverse transcription-PCR}

Total RNA was isolated from cultured fibroblasts using TRIzol Reagent (Invitrogen Life Technologies Inc., USA) following the protocol provided by the manufacturer. RNA was dissolved in RNase free water for RNA quality determination by UV spectrophotometer at the ratio of 260/280. Reverse transcription was performed with Omniscript ${ }^{\mathbb{R}}$ Reverse Transcription Kit (Qiagen GmbH, Germany) including Omniscript Reverse Transcriptase, 10× RT-PCR Buffer, 5 mM dNTP Mix and Oligo $d(T)_{18}$. Quantitative real-time PCR for type I, type III procollagen, TGF- $\beta 1$ and connective tissue growth factor (CTGF) was performed using ABI PRISM ${ }^{\mathbb{B}} 7300$ Sequence Detection System (Applied Biosystems, CA, USA). Aliquot of $2 \mu \mathrm{L}$ of the oligo dT-primed cDNA was amplified by PCR in a $20 \mu \mathrm{L}$ reaction mixture containing $0.5 \mu \mathrm{L}$ of $10 \mu \mathrm{M}$ of primers and $10 \mu \mathrm{L}$ SYBR $^{\mathbb{R}}$ Green PCR Master Mix (SYBR Green 1 Dye, AmpliTaq Gold ${ }^{\mathbb{B}}$ DNA Polymerase, dNTPs with dUTP, Passive Reference 1, and buffer components). The primers used for amplification were listed in Table 1. PCR was performed using the thermal cycle protocol listed as follows: stage $1: 50{ }^{\circ} \mathrm{C}$ for $2 \mathrm{~min}$; stage 2: $95^{\circ} \mathrm{C}$ for $10 \mathrm{~min}$; stage 3: 40 repetitions of $95^{\circ} \mathrm{C}$ for $15 \mathrm{~s}, 58^{\circ} \mathrm{C}$ for $30 \mathrm{~s}, 72{ }^{\circ} \mathrm{C}$ for $45 \mathrm{~s}$; stage $4: 95^{\circ} \mathrm{C}$ for $15 \mathrm{~s}, 60^{\circ} \mathrm{C}$ for $1 \mathrm{~min}$.

\subsection{Constituents analysis}

Extraction and HPLC analysis of isoflavonoids were performed as described by Ma et al. [23] with some modification. Five gram of the freeze-dried sample was extracted three times with $100 \mathrm{~mL}$ of aqueous methanol for $2 \mathrm{~h}$. The combined $\mathrm{MeOH}$ extract was filtered and evaporated to dryness under vacuum. The viscous residue was stirred in $25 \mathrm{~mL}$ of hot water, and the suspension was partitioned with $10,7.5$, and then $5 \mathrm{~mL}$ of ethyl acetate. The ethyl acetate containing isoflavonoids was evaporated to dryness. The viscous residues was dissolved in $1 \mathrm{~mL}$ of $\mathrm{MeOH}$ and filtered through a Millipore filter unit before analyzed by HPLC. The HPLC was performed on a Finnigan SpectraSYSTEM liquid chromatography system (Thermo Scientific, USA). The system included a quaternary pump, an UV detector, an autosampler, and was controlled by ChromQuest chromatography software. An Inertsil ODS-2 column $(250 \mathrm{~mm} \times 4.6 \mathrm{~mm}$ i.d; $5 \mu \mathrm{m})$ was used for the separation. The mobile phases consisted of water (A) and acetonitrile (B) each containing a

Table 1

Real-time RT-PCR primer sequence of target genes designed by the software of Applied Bioscience Prism 7300 sequence detection system.

\begin{tabular}{|c|c|c|c|c|}
\hline Target gene $(\mathrm{H})$ & GenBank identifier & Forward primer & Reverse primer & Amplicon size (bp) \\
\hline$\beta$-Actin & NM_001101.2 & GCTCCTCCTGAGCGCAAG & CATCTGCTGGAAGGTGGACA & 75 \\
\hline Type I procollagen & AF017178 & GAACGCGTGTCATCCCTTGT & GAACGAGGTAGTCTTTCAGCAACA & 94 \\
\hline Type III procollagen & $\mathrm{X} 14420$ & AACACGCAAGGCTGTGAGACT & GCCAACGTCCACACCAAATT & 88 \\
\hline TGF- $\beta 1$ & NM_000660 & ACAATTCCTGGCGATACCTCA & GGCGAAAGCCCTCAATTTC & 129 \\
\hline CTGF & NM_001901 & АСТСССААААТСТССАAGССТАТ & ATCGGCCGTCGGTACATACT & 100 \\
\hline
\end{tabular}


volume fraction of $0.1 \%$ glacial acetic acid, and the gradient elution program used was: $5-70 \% \mathrm{~B}(\mathrm{v} / \mathrm{v})$ at $0-30 \mathrm{~min}, 70-85 \% \mathrm{~B}$ at $30-45 \mathrm{~min}, 85-5 \% \mathrm{~B}$ at $45-55 \mathrm{~min}$, and the re-equilibration time of gradient elution was $10 \mathrm{~min}$. Elution was performed at a flow rate of $1.0 \mathrm{~mL} / \mathrm{min}$ at $25^{\circ} \mathrm{C}$ and detection at $280 \mathrm{~nm}$. Ononin, calycosin, and formononetin (ChromaDex, Santa Ana, USA) were identified by comparison of the HPLC retention time and the UV spectra of the authentic compounds. The calibration curve obtained by the authentic compounds was used for determining the concentration of isoflavonoids in the sample.

\subsection{Data and statistical analysis}

All data are means of at least triplicates \pm standard derivation (S.D.). Statistical analysis was performed using ANOVA, Duncan and Dunnett test (SAS Institute Inc., Cary, NC, USA) to determine significant differences among means and $p$-values less than 0.05 were considered statistically significant.

\section{Results}

\subsection{Effect of $H Q B$ and $H Q N B$ on collagenase, gelatinase, and elastase inhibition}

In the process of skin aging, expression of MMPs increases, causing more collagen degradation and resulting in aged skin with wrinkle and skin laxity [24,25]. MMPs are a family of zincrequiring endoproteases capable of degrading the components of extracellular matrix. At present, the MMPs family can be divided into several groups, such as MMP-1 (collagenase), MMP-2 (gelatinases), MMP-3 (stromelysins) and MMP-12 (metalloelastase), according to their substrate specificity and primary structure [26]. This study examined the abilities of fermented (HQB) and non-fermented (HQNB) preparations to inhibit the activities of collagenase, gelatinase, and elastase (Fig. 1). The inhibition rates of HQB for collagenase, gelatinase, and elastase at a concentration of $800 \mu \mathrm{g} / \mathrm{mL}$ were $26.55 \%, 24.87 \%$, and $12.58 \%$, respectively. The inhibition rates of HQNB were $28.95 \%, 24.45 \%$, and $7.25 \%$ for those three enzymes at the same levels, respectively. The inhibitory effects of both HQB and HQNB on collagenase and gelatinase were higher than that on elastase. There were significant difference between the inhibitory effects of HQB and HQNB on both collagenase and elastase $(p<0.05)$.

\subsection{Effect of $H Q B$ and $H Q N B$ on cell viability}

Even though $R$. astragali is considered as a top-grade herb (the herb without adverse effect) in traditional Chinese medicine, this study still needed to verify that HQB and HQNB are of low toxicity.

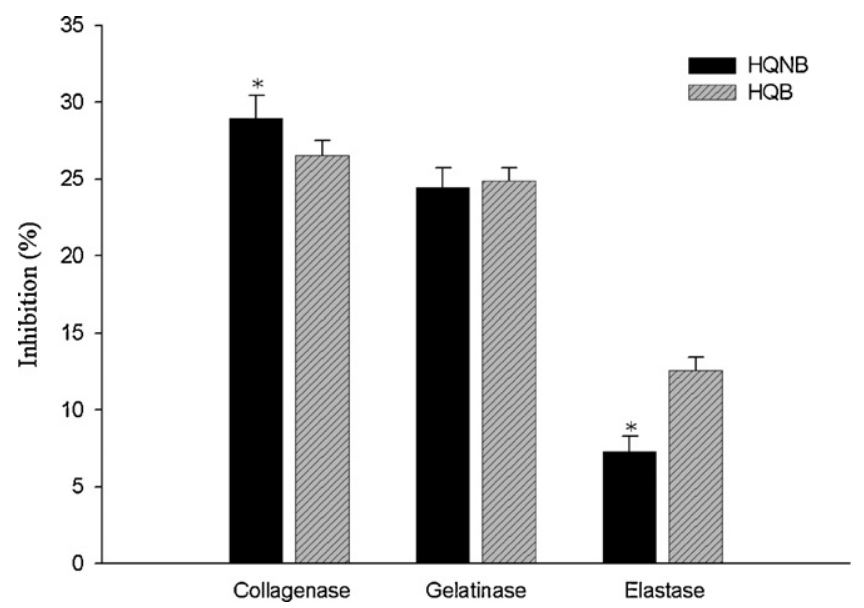

Fig. 1. Inhibition effects of $\mathrm{HQNB}$ and $\mathrm{HQB}(800 \mu \mathrm{g} / \mathrm{mL})$ on collagenase, gelatinase, and elastase. Results are expressed as mean \pm S.D., ${ }^{*} p<0.05$ : significant differences between HQB and HQNB for each enzyme. The results were verified by the repetition of three independent experiments, each in triplicate.

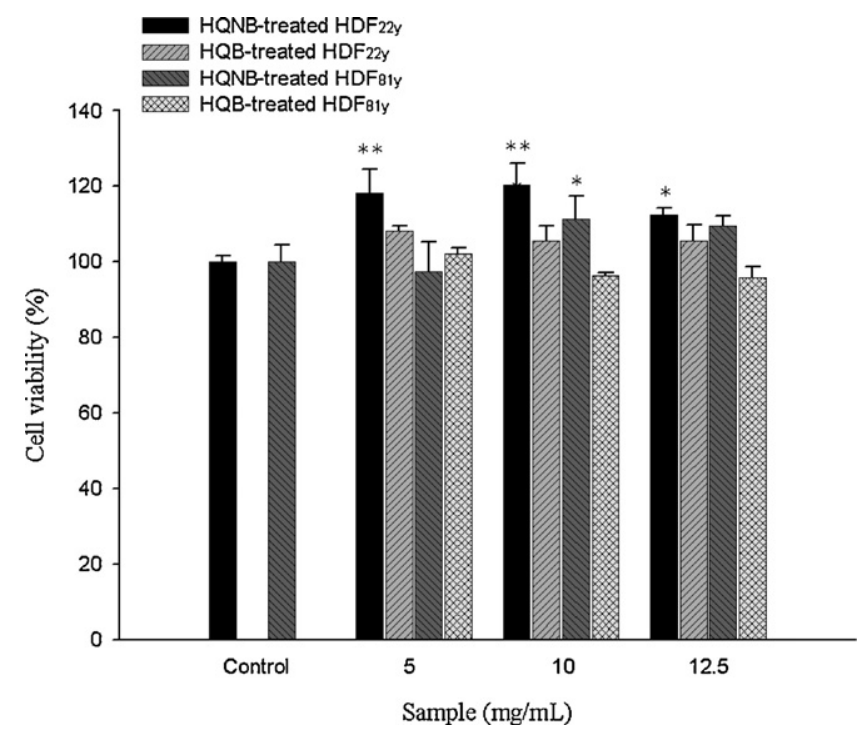

Fig. 2. The cytotoxicity of human dermal fibroblasts $\left(\mathrm{HDF}_{22 \mathrm{y}}\right.$ and $\left.\mathrm{HDF}_{81 \mathrm{y}}\right)$ treated with various concentrations of HQNB or HQB for $72 \mathrm{~h}$. Cell viability was determined by MTT assay as described in Section 2. The results are expressed as mean \pm S.D., $p<0.05,{ }^{* *} p<0.01$ : compared with control group (culture medium only). The results were verified by the repetition of three independent experiments, each in triplicate.

The MTT assay was performed to evaluate cytotoxic effects of HQB and HQNB on human dermal fibroblasts (HDF). HQB and HQNB showed relatively low cytotoxicity, the cell viability was above $95 \%$ with a concentration of $12.5 \mathrm{mg} / \mathrm{mL}$ (Fig. 2).

The effects of culture time and dosage of HQB and HQNB on proliferation of the two HDF cells were shown in Fig. 3. Compared with un-treated cells, HQB- and HQNB-treated cells showed greater potential of growth and proliferation during the culture period $(p<0.05)$. It is interesting to note that both HQB and HQNB showed a higher potency on the growth of $\mathrm{HDF}_{22 \mathrm{y}}$ cells than that on $\mathrm{HDF}_{81 \mathrm{y}}$ cells, and $\mathrm{HQNB}$-treated $\mathrm{HDF}_{22 \mathrm{y}}$ cells showed the highest proliferation rate among all treated cells $(p<0.05)$ (Fig. 3A). The effects of various concentrations $(100,500$, and $2000 \mu \mathrm{g} / \mathrm{mL}$ ) of HQB and HQNB on the proliferation of both HDF cells were depicted in Fig. 3B. After $72 \mathrm{~h}$ of incubation, both HQB and HQNB enhanced HDF cells proliferation in a dose-dependent manner. At the concentration of $500 \mu \mathrm{g} / \mathrm{mL}$, the growth rate of HQNB-treated $\mathrm{HDF}_{22 \mathrm{y}}$ and $\mathrm{HDF}_{81 \mathrm{y}}$ cells increased $26 \%$ and $15 \%$, respectively.

\subsection{Effect of $H Q B$ and $H Q N B$ on type I procollagen biosynthesis activity in cultured human dermal fibroblasts}

Collagen in the skin is synthesized by dermal fibroblasts. When the procollagen transcribed from collagen mRNA is secreted outside the cell, the propeptide at the carboxy or amino terminals of the procollagen is excised by a protease, which results in $\mathrm{pN}$ or pC collagen with only an amino or carboxy terminal. Because both $\mathrm{pN}$ and $\mathrm{pC}$ collagen are precursor molecules of mature collagen, the amount of propeptide reflects the level of collagen biosynthesis $[27,28]$.

We used an enzyme-linked immunosorbent assay (ELISA) to evaluate the potential effects of HQB and HQNB on the type I procollagen production in HDF cells. As shown in Fig. 4A, HQB $(500 \mu \mathrm{g} / \mathrm{mL})$ significantly enhanced type I procollagen production in both HDF cells in a time-dependent manner, and its stimulating effect was more pronounced than those of HQNB-treated or untreated cells $(p<0.05)$. For dose response $(50,100,500$, and 


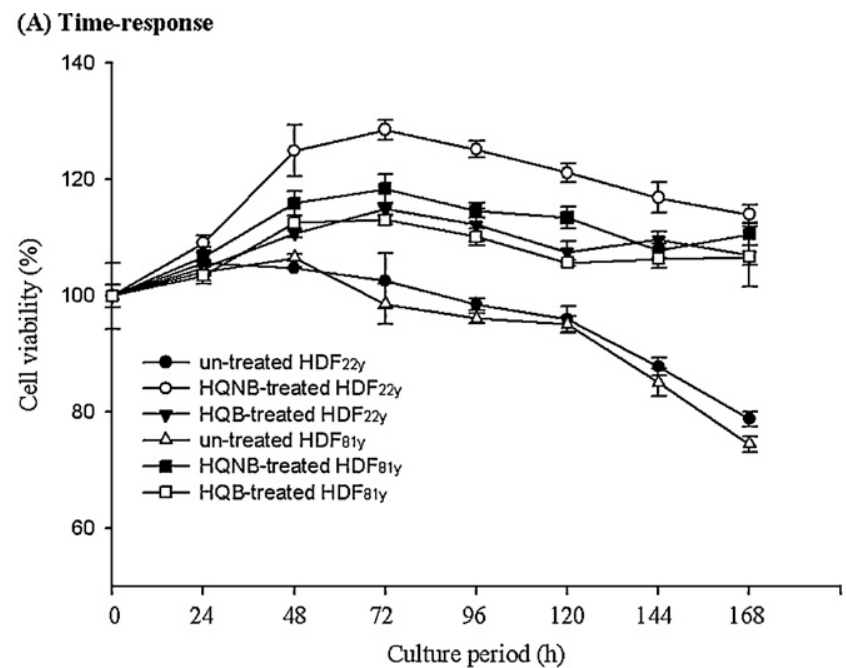

(B) Dose-response

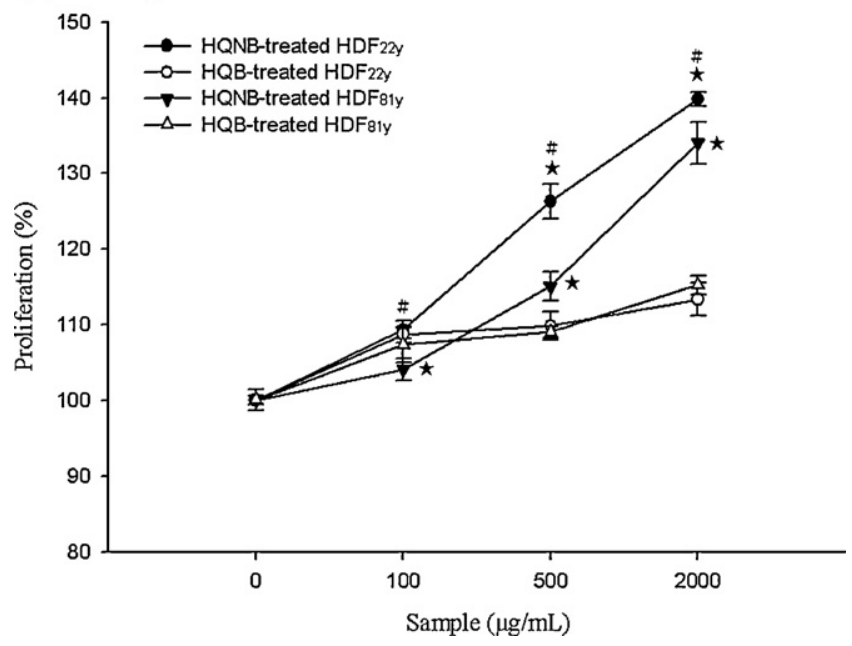

Fig. 3. Effects of $H Q N B$ or $H Q B$ on proliferation of human dermal fibroblasts $\left(\mathrm{HDF}_{22 \mathrm{y}}\right.$ and $\mathrm{HDF}_{81 \mathrm{y}}$ ) in MTT assay. (A) For time response studies, cells were treated with HQNB or HQB $(500 \mu \mathrm{g} / \mathrm{mL})$ for different time periods. (B) For dose response studies, cells were treated with various concentrations of HQNB or HQB for $72 \mathrm{~h}$. The results are expressed as mean \pm S.D., $(\star) p<0.05$ : significant differences between HQNB- and HQB-treated of each HDF cell type. ${ }^{\#} p<0.05$ : significant differences between $\mathrm{HDF}_{22 \mathrm{y}}$ and $\mathrm{HDF}_{81 \mathrm{y}}$ cells in $\mathrm{HQNB}$-treated groups. The results were verified by the repetition of three independent experiments, each in triplicate.

$1000 \mu \mathrm{g} / \mathrm{mL}$ ) studies, HQB exhibited a stimulating effect on the production of type I procollagen in both HDF cells in a concentration-dependent manner (Fig. 4B). In addition, the type I procollagen enhancing effect of HQB was significantly greater in $\mathrm{HDF}_{81 \mathrm{y}}$ cells than in $\mathrm{HDF}_{22 \mathrm{y}}$ cells $(p<0.05)$. The HQB treatment $(500 \mu \mathrm{g} / \mathrm{mL}$ ) increased the type I procollagen production by $152 \%$ and $84 \%$ in $\mathrm{HDF}_{81 \mathrm{y}}$ cells and in $\mathrm{HDF}_{22 \mathrm{y}}$ cells, respectively, as compared with the un-treated cells. Furthermore, the stimulation potential of $\mathrm{HQB}$ on $\mathrm{HDF}_{81 \mathrm{y}}$ cells was about 2.6-fold that of HQNB at the same concentration.

Type I procollagen protein levels in both HDF cells were examined using Western blot analysis. Cells were treated with different concentrations of $\operatorname{HQB}$ and $\operatorname{HQNB}(100,500$, and $1000 \mu \mathrm{g} /$ $\mathrm{mL}$ ) for $120 \mathrm{~h}$ to study dose response effect. Similarly, HQB had a more pronounced effect on enhancing the type I procollagen protein expression than the HQNB. In addition, the concentrationdependent effect on both HDF cells was observed for HQB. Also, the expression of type I procollagen protein enhanced by HQB was

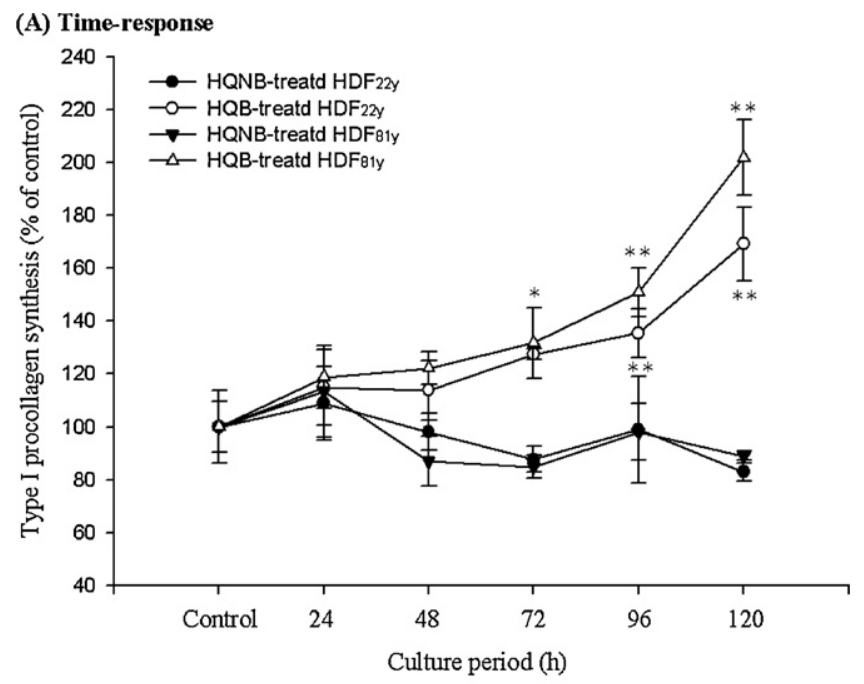

(B) Dose-response

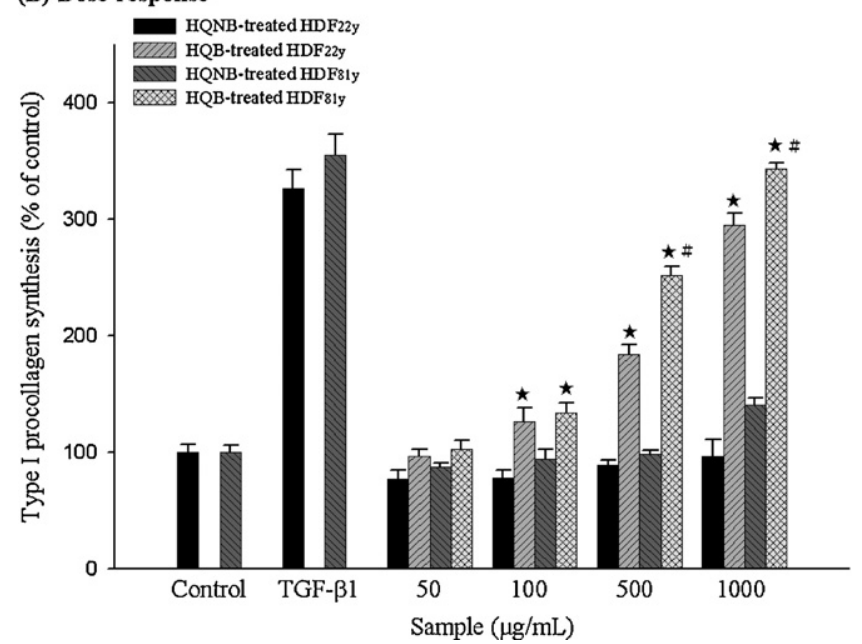

Fig. 4. Effects of HQNB or HQB on type I procollagen production in human dermal fibroblasts $\left(\mathrm{HDF}_{22 \mathrm{y}}\right.$ and $\left.\mathrm{HDF}_{81 \mathrm{y}}\right)$. (A) For time response studies, cells were treated with HQNB or HQB $(500 \mu \mathrm{g} / \mathrm{mL})$ and then the culture supernatant was collected at different time points. (B) For dose response studies, cells were treated with various concentrations of HQNB or HQB for $120 \mathrm{~h}$ and then the culture supernatant was collected. Type I procollagen synthesis was determined by ELISA kit as described in Section 2 . The results are expressed as mean \pm S.D., $p<0.05,{ }^{* *} p<0.01$ : compared with control group (culture medium only). $(\star) p<0.05$ : significant differences between HQNB- and HQB-treated of each HDF cell type. ${ }^{\#} p<0.05$ : significant differences between $\mathrm{HDF}_{22 \mathrm{y}}$ and $\mathrm{HDF}_{81 \mathrm{y}}$ cells in $\mathrm{HQB}$-treated groups. The results were verified by the repetition of three independent experiments, each in triplicate.

more pronounced in $\mathrm{HDF}_{81 \mathrm{y}}$ cells than in $\mathrm{HDF}_{22 \mathrm{y}}$ cells $(p<0.05)$. The HQB treatment ( $1000 \mu \mathrm{g} / \mathrm{mL}$ ) increased the expression of type I procollagen protein in $\mathrm{HDF}_{81 \mathrm{y}}$ and $\mathrm{HDF}_{22 \mathrm{y}}$ cells by $73 \%$ and $58 \%$, respectively $(p<0.05)$, as compared with the un-treated cells (Fig. 5A and B).

\subsection{Effect of $H Q B$ and $H Q N B$ on type I and type III procollagen $m R N A$ expression in cultured human dermal fibroblasts}

To further establish whether HQB enhanced type I procollagen biosynthesis via regulation at transcriptional or post-translational level, more experiments were necessary. Both HDF cells were treated with $500 \mu \mathrm{g} / \mathrm{mL}$ of HQB or HQNB separately, and the total RNA of the cells was extracted after incubation for $48 \mathrm{~h}$. The expression of type I procollagen and type III procollagen mRNA in cells was determined using real-time reverse transcription-polymerase chain reaction 
(A) $\mathrm{HDF}_{22 \mathrm{y}}$ cells

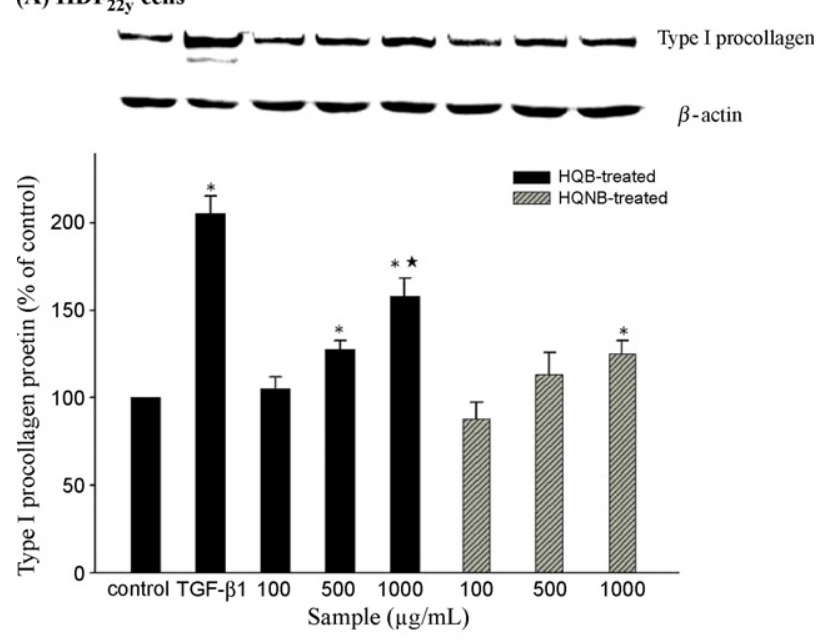

(B) $\mathrm{HDF}_{81 \mathrm{y}}$ cells

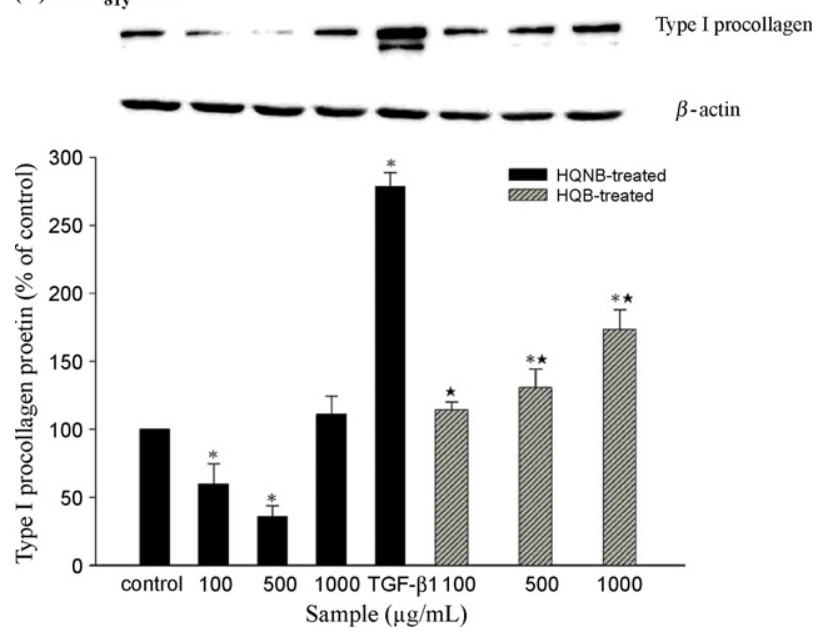

Fig. 5. Effects of HQNB or HQB on type I procollagen protein expression in human dermal fibroblasts $\left(\mathrm{HDF}_{22 \mathrm{y}}\right.$ and $\left.\mathrm{HDF}_{81 \mathrm{y}}\right)$. Cells were treated with various concentrations of HQB or HQNB for $120 \mathrm{~h}$, after which cells were harvested and total cell lysates were prepared for Western blot analysis, as detailed in Section 2 . $\beta$ Actin was used as a loading control. (A) $\mathrm{HDF}_{22 \mathrm{y}}$ cells and (B) $\mathrm{HDF}_{81 \mathrm{y}}$ cells. The results are expressed as mean \pm S.D., " $p<0.05$ : compared with control group (culture medium only). $(\star) p<0.05$ : significant differences between HQNB- and HQB-treated cells. The results were verified by the repetition of three independent experiments, each in triplicate. The autoradiographys in the upper show representative experiments.

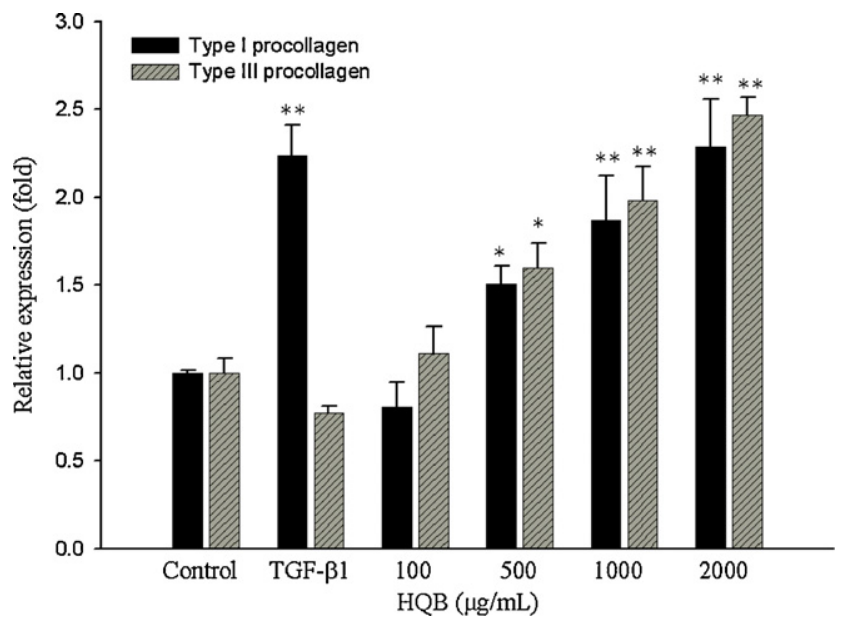

Fig. 6. Dose response of $\mathrm{HQB}$ on type I and type III procollagen mRNA expression in human dermal fibroblasts $\left(\mathrm{HDF}_{81 \mathrm{y}}\right) \cdot \mathrm{HDF}_{81 \mathrm{y}}$ cells were treated with various concentrations of HQB for $48 \mathrm{~h}$. The comparative changes in gene expression of type I and type III procollagen were determined by real-time RT-PCR analysis, as described in Section 2. Values were normalized using $\beta$-actin mRNA levels as a reference. The results are expressed as mean \pm S.D., $p<0.05,{ }^{* *} p<0.01$ : compared with control group (culture medium only). The results were verified by the repetition of three independent experiments, each in triplicate.

(RT-PCR). It was found that HQB significantly up-regulated type I and type III procollagen mRNA expression of $\mathrm{HDF}_{81 y}$ cells $(p<0.05)$ (Table 2). In addition, the expression of type III procollagen was slightly higher than that of type I procollagen in both HQB-treated cells. In contrast, there was no marked expression of these two kinds of procollagen mRNA in HQNB-treated cells. Furthermore, HQB showed dose-dependent effects on the expression of type I and type III procollagen mRNA in $\mathrm{HDF}_{81 \mathrm{y}}$ cells $(p<0.05)$ (Fig. 6).

\subsection{Effect of $H Q B$ and HQNB on TGF- $\beta 1$ and CTGF $m R N A$ expression in cultured human dermal fibroblasts}

To study the up-regulation mechanism of HQB-induced procollagen expression, the effects of fermented and nonfermented samples on the expression of TGF- $\beta 1$ and connective tissue growth factor (CTGF) in both HDF cells were investigated. Quantitative RT-PCR analysis revealed that HQB $(500 \mu \mathrm{g} / \mathrm{mL})$ significantly increased TGF- $\beta 1$ mRNA expression in $\mathrm{HDF}_{81 \mathrm{y}}$ cells after $12 \mathrm{~h}$ of incubation $(p<0.05)$ (Table 2$)$. However, similar to

Table 2

Effects of HQNB or HQB on type I, type III procollagen, TGF- $\beta 1$, and CTGF mRNA expression in human dermal fibroblasts (HDF $81 \mathrm{y}$ ).

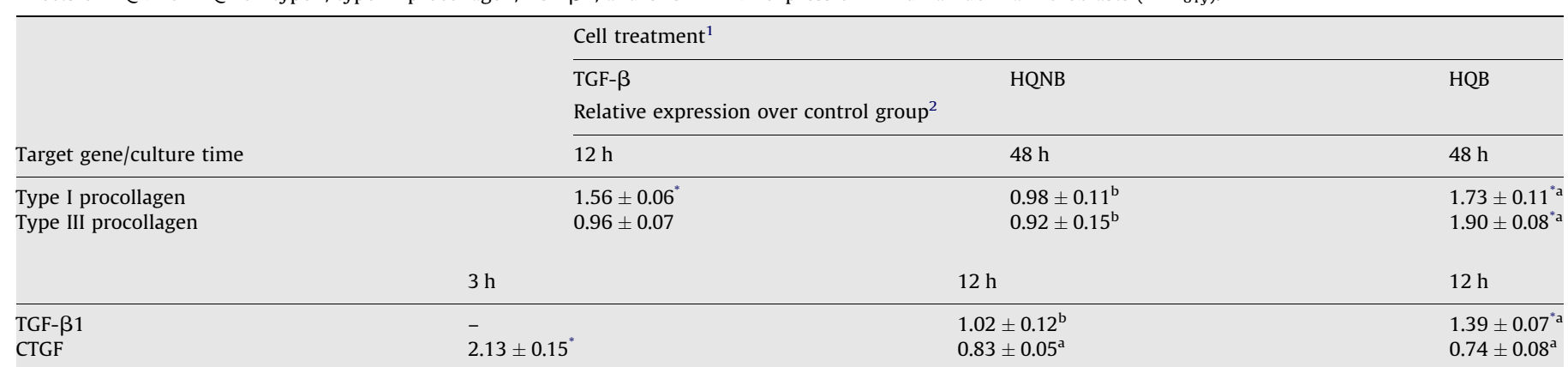

1 HDF cells were treated with $500 \mu \mathrm{g} / \mathrm{mL}$ of HQNB or HQB or $10 \mathrm{ng} / \mathrm{mL}$ of TGF- $\beta$ (positive control).

2 The comparative changes in gene expression of type I, type III procollagen, TGF- $\beta 1$, and CTGF were determined by real-time RT-PCR analysis, as described in Section 2. Values were normalized using $\beta$-actin mRNA levels as a reference. The results are expressed as mean \pm S.D.

$p<0.05$ : compared with control group (culture medium only). Mean with different letters (a, b) within the same culture time are significantly different among HQNBand HQB-treated groups for each target gene. The results were verified by the repetition of three independent experiments, each in triplicate. 


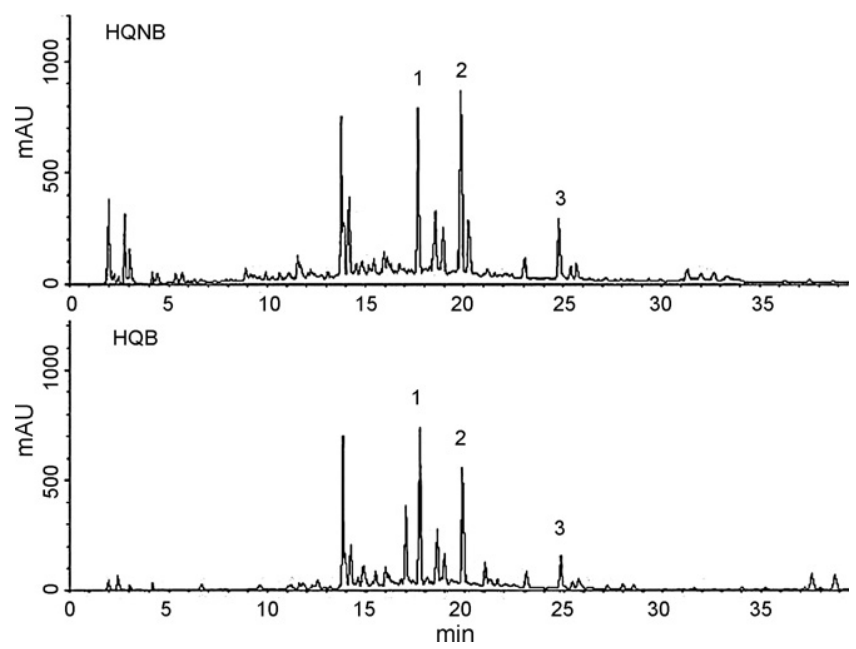

Fig. 7. The HPLC profiles of isoflavonoids in HQB and HQNB. (1) ononin; (2) calycosin; (3) formononetin.

Table 3

Contents of isoflavonoids in HQNB and HQB.

\begin{tabular}{lllr}
\hline Samples & \multicolumn{3}{l}{ Isoflavonoids $(\mu \mathrm{g} / \mathrm{g})(n=3)$} \\
\cline { 2 - 4 } & Ononin & Calycosin & Formononetin \\
\hline HQNB & $194.08 \pm 7.78^{\mathrm{a}}$ & $99.62 \pm 1.76^{\mathrm{a}}$ & $30.71 \pm 2.81^{\mathrm{a}}$ \\
HQB & $173.46 \pm 8.25^{\mathrm{b}}$ & $59.85 \pm 3.01^{\mathrm{b}}$ & $7.68 \pm 0.37^{\mathrm{b}}$ \\
\hline
\end{tabular}

a,b Means with different letters within a column are significantly different $(p<0.05)$.

the observations on the expression of type I and type III procollagen mRNA, HQNB was not able to induce TGF- $\beta 1$ mRNA expression in both HDF cells. Also shown in Table 2, TGF- $\beta 1$ significantly elevated the levels of CTGF mRNA in HDF $_{81 y}$ cells $(p<0.05)$ after $3 \mathrm{~h}$ of incubation. However, both of the fermented and non-fermented samples did not significantly affect the levels of CTGF mRNA in both HDF cells $(p>0.05)$.

\subsection{Changes of isoflavonoids in $R$. astragali after fermentation}

It has been revealed that isoflavonoids is one of the major bioactive components in $R$. astragali responsible for pharmacological activities and therapeutic efficacy $[8,9]$. Hence, the isoflavonoids compositions of HQB and HQNB were determined by HPLC, and their chromatographic profiles were shown in Fig. 7. There were three major active isoflavonoids, identified as ononin, calycosin, and formononetin found in $R$. astragali. After fermentation, all of these three compounds were significantly reduced as shown in Table $3(p<0.05)$.

\section{Discussion}

Chinese herbs have been used in clinical applications for many centuries. Driven by rising consumer interest and demand for natural products, there has been great interest and attention in the application of Chinese herbs in the development of skincare cosmetics [29]. Currently, various Chinese herbs are used in skin care cosmetics and claimed that they can improve the physical appearance of aged skin. To our knowledge, however, few claims are based on substantial scientific evidence. Since the ethnobotanical data revealed that $R$. astragali has been used clinically as skin applications [30], and microbial fermentation might be a useful tool to enhance the skin care function of Chinese herbs, this study investigated the effects of the non-fermented and fermented $R$. astragali on the biosynthesis of collagen in human dermal fibroblasts.

Skin, like all other organs, ages with time progresses. It is known that the mechanism for skin photoaging is due to the production of reactive oxygen species (ROS) induced by UV irradiation. The activation of ROS leads to a series of signal transduction and stimulate the gene transcription of matrix-degrading enzymes, such as MMP-1 (collagenase) and MMP-9 (gelatinase) [1,31]. On the other hand, the mechanism for chronological aging is not as well understood as that for photoaging. It has been reported that chronological aging is at least partially due to ROS-induced MMPs activation and to the slow proliferation of fibroblasts [32-34]. Nevertheless, both chronological aging and photoaging involve the expression and degradation of several molecules participating in the metabolism of the connective tissue, including changes in the amount of ECM components (e.g. collagen and elastin), and in MMPs activity.

The balance of collagen synthesis and degradation is crucial to the synthesis of collagen in human skin. Our study showed that HQB and HQNB $(800 \mu \mathrm{g} / \mathrm{mL})$ inhibited enzyme activities of collagenase, gelatinase and elastase, and the inhibitory effects on collagenase and gelatinase (24-28\%) were significantly higher than that on elastase (12-7\%). An et al. [6] reported that 100 and $500 \mu \mathrm{g} / \mathrm{mL}$ of persimmon leaf extract inhibited collagenase and elastase activity by $15.2 \%$ and $78.1 \%$, respectively. Kim et al. [35] demonstrated that even $10 \mathrm{ppm}$ of soy isoflavones could inhibit the UVB-induced expression of MMP- 1 in fibroblasts. Oral feeding of polyphenols $(0.2 \%)$ extracted from green tea to SKH-1 hairless mice also resulted in inhibition of UVB-induced expression of matrix-degrading MMPs, such as MMP-2 (67\%) and MMP-3 (63\%) [36]. It appeared that the inhibitory effects of $\mathrm{HQB}$ on collagenase, gelatinase, and elastase activities were not as prominent as the samples investigated in the above-mentioned studies. Hence, it appeared that the role of $\mathrm{HQB}$ in the skincare function is largely rely on its effect on the collagen synthesis, but not on its inhibitory effect of collagen degradation.

It has been reported that the growth potential of fibroblasts isolated from tissue fragments of different donor age declined with increasing age, but increased by 3 -fold after topical application of $1 \%$ retinol on $80+y$ old individuals for $7 \mathrm{~d}$ [37]. Our study showed that the non-fermented $R$. astragali (HQNB, $500 \mu \mathrm{g} / \mathrm{mL}$ ) increased the growth of $\mathrm{HDF}_{22 \mathrm{y}}$ and $\mathrm{HDF}_{81 \mathrm{y}}$ cells by 1.26 - and 1.15 -fold, respectively. Chinese herbs generally contain amino acids, trace elements, polyphenols, flavonoids, saponins, and other bioactive ingredients which have been demonstrated to be able to enhance proliferation, DNA expression, protein synthesis and metabolism rate of cells [38,39]. The 4-hydroxy-5-hydroxymethyl-[1,3]dioxolan-2,6-spirane-5,6,7,8-tetrahydro-indolizine-3-carbaldehyde (HDTIC) extracted from $R$. astragali showed the senescencedelaying effect on human fibroblasts by its potentials of proliferation improvement, inhibitory effect of advanced glycation end products formation, and its antioxidant activity [13]. Together, these findings and the results of our study suggested that $R$. astragali was one of the effective anti-aging Chinese herbs.

In the culture of human dermal fibroblasts, fermented (HQB), but not non-fermented $R$. astragali (HQNB), significantly and dosedependently (50-1000 $\mu \mathrm{g} / \mathrm{mL}$ ) elevated the expression of mRNA and protein for type I and type III procollagen. Contrary to the cell proliferation effect, HQB showed a greater enhancing activities on type I procollagen mRNA expression and protein synthesis in $\mathrm{HDF}_{81 \mathrm{y}}$ cells, compared with $\mathrm{HDF}_{22 \mathrm{y}}$ cells. Although the type I collagen is the predominant collagen found in skin (ca. 80\%), type III collagen (15\%) is the major collagen responsible for the elastic properties in human skin. Interestingly, we found that HQB had 
more pronounced effect on the expression of type III procollagen mRNA in both HDF cells than that on type I procollagen mRNA. Furthermore, the results of real-time RT-PCR analysis revealed that the effect of HQB on procollagen production in HDF cells was by transcriptional regulation. On the other hand, HQNB did not induce the expression of procollagen mRNA and protein, even though it showed a significant proliferation effect on both HDF cells. These results demonstrated that fermentation is indeed a potential method for enhancing the skincare function of traditional Chinese herbal medicines.

It is well known that TGF- $\beta 1$ promotes collagen synthesis $[40,41]$. Much evidence indicates that the inductive effects of TGF$\beta 1$ on procollagen production are mediated by CTGF $[42,43]$. Here we demonstrated that $500 \mu \mathrm{g} / \mathrm{mL}$ of HQB significantly increased the levels of TGF- $\beta 1$ mRNA in $\mathrm{HDF}_{81 \mathrm{y}}$ cells, but had no effect on CTGF expression. These observations indicated that TGF- $\beta 1$ transcripts induced by HQB might be partially responsible for the stimulation of procollagen expression in cultured HDF cells. Holmes et al. [44] have identified a functional Smad binding site in the CTGF promoter. Induction of CTGF by TGF- $\beta 1$ is dependent on Smad3 and Smad4 but not Smad2. In the mean time, studies have shown that TGF- $\beta$-induced expression of type I collagen is mediated via the Smad signal transduction pathway as well as phosphatidylinositol-3 (PI-3) kinase/Akt/mTOR pathway in human dermal fibroblasts [45-47]. Akt activation, however, suppresses activation of Smad3 in an Akt kinase-dependent manner through mTOR [48]. Therefore, we suspected that TGF- $\beta 1$-induced expression of procollagen in HQB-stimulated fibroblasts might be through PI-3 kinase/Akt/mTOR-dependent pathway, which suppress CTGF expression.

As shown in Table 2, HQNB had little effect on TGF- $\beta 1$ mRNA expression, but showed potent mitogenic activity in HDF cells (Fig. 3A, B). Recent studies indicated that estrogen- (17 $\beta$-estradiol) and phytoestrogen- (genistein, ginsenoside Rg1) stimulated mitogenesis in human breast cancer cells (MCF-7) could also be mediated by the enhancement of IGF-1 receptor (IGF-1R) signaling pathway [49-52]. It was supported by the up-regulation of IGF-1R and insulin-receptor substrate expressions which appeared to require estrogen receptor in MCF-7 cells treated with estrogen or phytoestrogen. In addition, formononetin, an isoflavonoid phytoestrogen, can induce the expression of the estrogen-responsive reporter gene in MCF-7 cells, as well as the proliferation of MCF-7 cells and mammary gland $[53,54]$. In this study, there were three major active isoflavonoids, identified as ononin, calycosin, and formononetin found in HQNB (Table 3 ). Since earlier investigations have shown that estrogen receptor does exist in the culture of human skin fibroblasts [55], therefore, we speculated that the mitogenic activity of HQNB in fibroblasts might be mediated by the activation of crosstalk between estrogen receptor and IGF-1R signaling cascade. In the mean time, we cannot yet exclude the possibility that other signaling pathway is also involved in the proliferative effect of HQNB on HDF cells. Future study is needed to elucidate the detailed mechanism as well as to provide insights for understanding the complex actions of both HQB and HQNB in HDF cells.

Hormone replacement therapy is one of the current available therapeutic approaches for aging skin [56]. It has been reported that genistein $[7,57,58]$, asiaticoside $[5,59]$, and ginsenosides metabolites [60] enhanced the biosynthesis of collagen and hyaluronic acid in human skin cells. The flavonoids found in $R$. astragali mainly consist of isoflavones, of which calycosin, formononetin, and ononin are three known major components. In this study, we found that the content of calycosin, formononetin and ononin in HQB was much less than that in HQNB, suggesting that $\beta$-glucosidase from $B$. subtilis natto might have converted these isoflavones to aglycones during fermentation, and the produced aglycones from their respective glycosides might be the bioactive components, at least partially, responsible for the skincare functions found in this study. However, due to the complexity of the constituents in the fermentation broth, further investigation is needed in order to identify all of the components in the fermented product which are responsible for the enhancing activities of HQB on procollagen synthesis in HDF cells.

\section{Conclusion}

This study provides positive and strong evidence in support of the enhancing activities of HQB on procollagen biosynthesis in human dermal fibroblasts isolated from human skin of two ages (22 y and $81 \mathrm{y}$ ). We demonstrated that the collagen biosynthesis enhancement is, at least in part, due to the mitogenic activity of $\mathrm{HQB}$ in HDF cells and the regulation of procollagen biosynthesis resulting from HQB-induced TGF- $\beta 1$ expression. Given the low toxicity and the stimulating effects on collagen production of $\mathrm{HQB}$, we expect that $\mathrm{HQB}$ may have a promising skincare application for internal and external uses. Further studies are required to identify the active components in HQB that are responsible for the positive effects on skin and the mechanisms of their skincare functions.

\section{Acknowledgement}

This work was supported by a grant, NSC 95-2313-B-002-091MY3, from the National Science Council, Executive Yuan, ROC.

\section{References}

[1] Fisher GJ, Kang S, Varani J, Bata-Csorgo Z, Wan Y, Datta S, et al. Mechanisms of photoaging and chronological skin aging. Arch Dermatol 2002;138:1462-70.

[2] Lupo MP. Cosmeceutical peptides. Dermatol Surg 2005;31:832-6.

[3] Dhalla AK, Hill MF, Singal PK. Role of oxidative stress in transition of hypertrophy to heart failure. J Am Coll Cardiol 1996;28:506-14.

[4] Coldren CD, Hashim P, Ali JM, Oh SK, Sinskey AJ, Rha C. Gene expression changes in the human fibroblast induced by Centella asiatica triterpenoids. Planta Med 2003;69:725-32.

[5] Lu L, Ying K, Wei S, Fang Y, Liu Y, Lin H, et al. Asiaticoside induction for cellcycle progression, proliferation and collagen synthesis in human dermal fibroblasts. Int J Dermatol 2004:43:801-7.

[6] An BJ, Kwak JH, Park JM, Lee JY, Park TS, Lee JT, et al. Inhibition of enzyme activities and the antiwrinkle effect of polyphenol isolated from the persimmon leaf (Diospyros kaki folium) on human skin. Dermatol Surg 2005;31: 848-54.

[7] Südel KM, Venzke K, Mielke H, Breitenbach U, Mundit C, Jaspers S, et al. Novel aspects of intrinsic and extrinsic aging of human skin: beneficial effects of soy extract. Photochem Photobiol 2005;81:581-7.

[8] Sinclair S. Chinese herbs: a clinical review of Astragalus, Ligusticum, and Schizandrae. Altern Med Rev 1998;3:338-44.

[9] Wagner H, Bauer R, Xiao PG, Chen JM, Michler G. Radix Astragali (Huang Qi). Chin Drug Monogr Anal 1997;1:1-17.

[10] Chen K, Li C. Recent advances in studies on traditional Chinese anti-ageing medica. J Tradit Chin Med 1993;13:223-6.

[11] Yamada H, Kiyohara H, Takemoto N, Zhao JF, Kawamura H, Komatsu Y, et al Mitogenic and complement activating activities of the herbal components of juzen-taiho-to. Planta Med 1992;58:166-70.

[12] Li LY, Chen MH, Tong TJ, Wang HY. The molecular basis of Chinese herbs (Astragali and Angelica) on increasing serum albumin synthesis in nephrotic rats. Nephrology 1998;4:373-8.

[13] Wang P, Zhang Z, Ma X, Huang Y, Liu X, Tu P, et al. HDTIC-1 and HDTIC-2, two compounds extracted from Astragali Radix, delay replicative senescence of human diploid fibroblasts. Mech Ageing Dev 2003;124:1025-34.

[14] Miyake Y, Fukumoto S, Okada M, Sakaida K, Nakamura Y, Osawa T. Antioxidative catechol lignans converted from sesamin and sesaminol triglucoside by culturing with Aspergillus. J Agric Food Chem 2005;53: 22-7.

[15] Nakano D, Kwak CJ, Fujii K, Ikemura K, Satake A, Ohkita M, et al. Sesamin metabolites induce an endothelial nitric oxide-dependent vasorelaxation through their antioxidative property-independent mechanisms: possible involvement of the metabolites in the antihypertensive effect of sesamin. J Pharmacol Exp Ther 2006:318:328-35.

[16] Lin YW, Chiang BH. Anti-tumor activity of the fermentation broth of Cordyceps militaris cultured in the medium of Radix astragali. Process Biochem 2008;43: 244-50. 
[17] Ibe S, Kumada K, Yoshiba M, Onga T. Production of natto which contains a high level of isoflavone aglycons. Nippon Shofuhin Kagaku Kogaku Kaishi 2001;48: 27-34.

[18] Hendrich S. Bioavailability of isoflavones. J Chromatogr B Analyt Technol Biomed Life Sci 2002;777:203-10.

[19] Kawakami Y, Tsurugasaki W, Nakamura S, Osada K. Comparison of regulative functions between dietary soy isoflavones aglycone and glucoside on lipid metabolism in rats fed cholesterol. J Nutr Biochem 2005;16:205-12.

[20] Izumi T, Piskula MK, Osawa S, Obata A, Tobe K, Saito M, et al. Soy isoflavone aglycones are absorbed faster and in higher amounts than their glucosides in humans. J Nutr 2000;130:1695-9.

[21] Chiba K, Kawakami K, Tohyama K. Simultaneous evaluation of cell viability by neutral red, MTT and crystal violet staining assays of the same cells. Toxicol In Vitro 1998;12:251-8.

[22] Chung JH, Seo JY, Choi HR, Lee MK, Youn CS, Rhie G, et al. Modulation of skin collagen metabolism in aged and photoaged human skin in vivo. J Invest Dermatol 2001;117:1218-24.

[23] Ma XQ Shi Q Duan JA, Dong TX, Tsim KWK. Chemical analysis of Radix Astragali (Huangqi) in China: a comparison with its adulterants and seasonal variations. J Agric Food Chem 2002;50:4861-6.

[24] Fisher GJ, Datta SC, Talwar HS, Wang ZQ, Varani J, Kang S, et al. The molecular basis of sun-induced premature skin aging and retinoid antagonism. Nature 1996;379:335-8.

[25] Fisher GJ, Wang ZQ, Datta SC, Varani J, Kang S, Voorhees JJ. Pathophysiology of premature skin aging induced by ultraviolet light. N Engl J Med 1997;337: 1419-28.

[26] Kähäri VM, Saarialho-Kere U. Matrix metalloproteinases in skin. Exp Dermatol 1997;6:199-213.

[27] Oikarinen A, Autio P, Kiistala U, Risteli L, Risteli J. A new method to measure type I and III collagen synthesis in human skin in vivo: demonstration of decreased collagen synthesis after topical glucocorticoid treatment. J Invest Dermatol 1992;98:220-5.

[28] Myllyharju J, Kivirikko KI. Collagens, modifying enzymes and their mutations in humans, flies and worms. Trends Genet 2004;20:33-43.

[29] Aburjai T, Natsheh FM. Plants used in cosmetics. Phytother Res 2003;17: 987-1000.

[30] Wang KH, Lin RD, Hsu FL, Huang YH, Chang HC, Huang CY, et al. Cosmetic applications of selected traditional Chinese herbal medicines. J Ethnopharmacol 2006;106:353-9.

[31] Angel P, Szabowski A, Schorpp-Kistner M. Function and regulation of AP-1 subunits in skin physiology and pathology. Oncogene 2001;20:2413-23.

[32] Sohal RS, Weindruch R. Oxidative stress, caloric restriction and aging. Science 1996;273:59-63.

[33] Hensley K, Floyd R. Reactive oxygen species and protein oxidation in aging: a look back, a look ahead. Arch Biochem Biophys 2002;397:377-83.

[34] Khorramizadeh MR, Tredget EE, Telasky C. Aging differentially modulates the expression of collagen and collagenase in dermal fibroblasts. Mol Cell Biochem 1999;194:99-108.

[35] Kim SY, Kim SJ, Lee JY, Kim WG, Park WS, Sim YC, et al. Protective effects of dietary soy isoflavones against UV-induced skin-aging in hairless mouse model. J Am Coll Nutr 2004;23:157-62.

[36] Vayalil PK, Mittal A, Hara Y, Elmets CA, Katiyar SK. Green tea polyphenols prevent ultraviolet light-induced oxidative damage and matrix metalloproteinases expression in mouse skin. J Invest Dermatol 2004; 122:1480-7.

[37] Varani J, Warner RL, Mehrnaz GK, Phan SH, Kang S, Chung JH, et al. Vitamin A antagonizes decreased cell growth and elevated collagen degrading matrix metalloproteinases and stimulates collagen accumulation in naturally aged human skin. J Invest Dermatol 2000;114:480-6.

[38] Fu Y, Wei S, Jin X. The research on the application of Chinese herb in cosmetics for anti-aging of the skin. Detergent Cosmet 1999;1:27-9.

[39] Benaiges A, Armengol R, Mateu B, Sagrista ML, Mora M. Effect of germinated seed extract on the respiratory activity of human skin fibroblasts and sheep liver mitochondria. Influence on cell viability and proliferation and their usefulness as active cosmetic ingredient. Int J Cosmet Sci 2001;23: 245-55.

[40] Eickelberg O, Kohler E, Reichenberger F. Extracellular matrix deposition by primary human lung fibroblasts in response to TGF-beta 1 and TGF-beta 3. Am J Physiol 1999;276:L814-24.

[41] Hall MC, Young DA, Waters JG, Rowan AD, Chantry A, Edwards DR, et al. The comparative role of activator protein 1 and Smad factors in the regulation of TIMP-1 and MMP-1 gene expression by transforming growth factor-beta 1 . J Biol Chem 2003;278:10304-13.

[42] Duncan MR, Frazier KS, Abramson S, Williams S, Klapper H, Huang X, et al. Connective tissue growth factor mediates transforming growth factor betainduced collagen synthesis: down-regulation by cAMP. FASEB J 1999;13 1774-86.

[43] Quan T, He T, Kang S, Voorhees JJ, Fisher GJ. Connective tissue growth factor: expression in human skin in vivo and inhibition by ultraviolet irradiation. J Invest Dermatol 2002;118:402-8.

[44] Holmes A, Abraham DJ, Sa S, Shiwen X, Black CM, Leask A. CTGF and SMADs, maintenance of scleroderma phenotype is independent of SMAD signaling. J Biol Chem 2001;276:10594-601.

[45] Varga J. Scleroderma and smads. Arthritis Rheum 2002;46:1703-13.

[46] de Obanos MP, Lopez Zabalza MJ, Prieto J, Herraiz MT, Iraburu MJ. Leucine stimulates procollagen $\alpha 1(\mathrm{I})$ translation on hepatic stellate cells through ERK and PI3K/Akt/mTOR activation. J Cell Physiol 2006;209:580-6.

[47] Kim S, Lee Y, Seo JE, Cho KH, Chung JH. Caveolin-1 increases basal and TGF-beta 1 -induced expression of type I procollagen through PI-3 kinase/Akt/mTOR pathway in human dermal fibroblasts. Cell Signal 2008;20:1313-9.

[48] Song K, Wang H, Krebs TL, Danielpour D. Novel roles of Akt and mTOR in suppressing TGF- $\beta$ /ALK5-mediated Smad3 activation. EMBO J 2006;25:58-69.

[49] Kahlert S, Nuedling S, van Eickels M, Vetter H, Meyer R, Grohe C. Estrogen receptor $\alpha$ rapidly activates the IGF- 1 receptor pathway. J Biol Chem 2000; 275:18447-53.

[50] Song RS, Zhang Z, Chen Y, Bao Y, Santen RJ. Estrogen signaling via a linear pathway involving insulin-like growth factor I receptor, matrix metalloproteinases, and epidermal growth factor to activate mitogen-activated protein kinase in MCF-7 breast cancer cells. Endocrinology 2007;148:4091-101.

[51] Chen WF, Wong MS. Genistein enhances insulin-like growth factor signaling pathway in human breast cancer (MCF-7) cells. J Clin Endocrinol Metab 2004 89:2351-9.

[52] Chen WF, Lau WS, Cheung PY, Guo DA, Wong MS. Activation of insulin-like growth factor I receptor-mediated pathway by ginsenoside Rg1. Br J Pharmacol 2006; 147:542-51.

[53] Wang W, Tanaka Y, Han Z, Higuchi CM. Proliferative response of mammary glandular tissue to formononetin. Nutr Cancer 1995;23:131-40.

[54] Ji ZN, Zhao WY, Liao GR, Choi RC, Lo CK, Dong TTX, et al. In vitro estrogenic activity of formononetin by two bioassay systems. Gynecol Endocrinol 2006; 22:578-84.

[55] Haczynski J, Tarkowski R, Jarzabek K, Slomczynska M, Wolczynski S, Magoffin DA, et al. Human cultured skin fibroblasts express estrogen receptor alpha and beta. Int J Mol Med 2002;10:149-53.

[56] Yaar M, Gilchrest BA. Skin aging: postulated mechanisms and consequent changes in structure and function. Clin Geriatr Med 2001;17:617-30.

[57] Miyazaki K, Hanamizu T, Iizuka R, Chiba K. Genistein and daidzein stimulate hyaluronic acid production in transformed human keratinocyte culture and hairless mouse skin. Skin Pharmacol Appl Skin Physiol 2002;15:175-83.

[58] Miyazaki K, Hanamizu T, Iizuka R, Chiba K. Bifidobacterium-fermented soy milk extract stimulates hyaluronic acid production in human skin cells and hairless mouse skin. Skin Pharmacol Appl Skin Physiol 2003;16:108-16.

[59] Lee J, Jung E, Kim Y, Park J, Park J, Hong S, et al. Asiaticoside induces human collagen I synthesis through TGF $\beta$ receptor I kinase (T $\beta R$ I kinase)-independent Smad signaling. Planta Med 2006;72:324-8.

[60] Kim S, Kang BY, Cho SY, Sung DS, Chang HK, Yeom MH, et al. Compound K induces expression of hyaluronan synthase 2 gene in transformed human keratinocytes and increases hyaluronan in hairless mouse skin. Biochem Biophys Res Commun 2004;316:348-55. 